\title{
ICONOGRAFIA PICTÓRICA HISTÓRICA E SEU DIÁLOGO COM O ENSINO DE HISTÓRIA
}

\author{
HISTORICAL PICTORIAL ICONOGRAPHY AND ITS DIALOGUE WITH THE \\ TEACHING OF HISTORY
}

Jucilmara Luiza Loos Vieira ${ }^{1}$

\begin{abstract}
RESUMO: Este artigo teve por meta mostrar a produção acadêmica na área do ensino de história, tendo como fundamento a relação entre a Iconografia Pictórica Histórica e o ensino da história. A finalidade principal foi verificar a possibilidade do diálogo entre essa produção, considerada como expressão de uma cultura histórica de uma sociedade e o processo de ensino e aprendizagem da história. O artigo foi organizado da seguinte forma: foram apresentadas algumas perspectivas teóricas e metodológicas orientadoras para identificação da produção e seu diálogo com o ensino de história. Apresentou-se uma contextualização com a intenção de explicar o significado de Iconografia Pictórica Histórica e como ela é a expressão da cultura histórica de uma sociedade. Definiu-se o termo cultura histórica e como a Iconografia Pictórica Histórica enquanto expressão da cultura histórica, tem relação com a formação da consciência histórica e, portanto, com o ensino e aprendizagem da história. Apresentou-se uma definição para Iconografia Pictórica Histórica e o termo cultura histórica foi explorado juntamente com os elementos que o compõe, sendo realizado um estudo sobre a consciência histórica e a aprendizagem histórica.
\end{abstract}

Palavras-chave: Educação histórica. Iconografia pictórica. Fonte histórica.

ABSTRACT: This article aimed to show the academic production in the area of history teaching, based on the relationship between Historic Pictorial Iconography and the teaching of history. The main purpose was to verify the possibility of the dialogue between this production, considered as an expression of a historical culture of a society and the process of teaching and learning of history. The article was organized as follows: some theoretical and methodological perspectives were presented to guide the identification of production and its dialogue with the teaching of history. A contextualization was presented with the intention of explaining the meaning of Historic Pictorial Iconography and how it is the expression of the historical culture of a society. The term historical culture was defined and as Historical Pictorial Iconography as an expression of historical culture, it is related to the formation of historical consciousness and, therefore, to the teaching and learning of history. A definition was presented for Historic Pictorial Iconography and the term historical culture was explored together with the elements that compose it, and a study on historical consciousness and historical learning was carried out.

Keywords: History education. Pictorial iconography. Historical source.

1 Professora QPM da Superintendência da Educação do Paraná. Mestre em Educação pela Universidade Federal do Paraná (UFPR). 


\section{Introdução}

As reflexões, aqui apresentadas, constituem parte de uma investigação realizada no mestrado em Educação da Universidade Federal do Paraná, com o título: "Cultura Histórica e Cultura Escolar: Diálogos entre a Iconografia Pictórica Histórica e o Ensino de História", sob orientação da professora doutora Maria Auxiliadora Moreira dos Santos Schmidt, no domínio científico da Educação Histórica. O presente trabalho demonstra a relação entre a Iconografia Pictórica Histórica e o ensino da história na produção acadêmica. Neste sentido, a produção acadêmica é aqui considerada como expressão de uma cultura histórica de uma sociedade e dialoga com o processo de ensino-aprendizagem de história.

O referido artigo permitiu explicar o significado de Iconografia Pictórica Histórica enquanto cultura histórica e como esta tem relação com a formação da consciência histórica, bem como com o ensino e aprendizagem da história. A pesquisa proporcionou uma definição para Iconografia Pictórica Histórica, bem como o termo cultura histórica foi explicado com seus elementos, partindo para um estudo da consciência histórica e da aprendizagem histórica.

\section{Perspectivas teóricas orientadoras para identificação da produção acadêmica sobre fontes visuais (pinturas históricas) e do seu diálogo com o ensino de história}

O ensino de história possui diferentes abordagens e práticas. Algumas concepções defendem que os estudantes conseguem compreender melhor se o ensino for pautado no uso de variadas fontes que possam conduzir a um processo de aprendizagem com significado. Algumas fontes acabam tornando-se mais significativas para o aprendizado do ensino de história quando representam o passado de forma artística, uma vez que podem contribuir para instigar a curiosidade dos alunos. De acordo com Aróstegui, fonte histórica seria, em princípio, todo aquele material, instrumento ou ferramenta, símbolo ou discurso intelectual, que procede da criatividade humana, através do qual se pode inferir 
algo acerca de uma determinada situação social no tempo (ARÓSTEGUI, 2006, p.491).

Entende-se por fonte histórica todo e qualquer tipo de material que possa remeter e testemunhar o passado, podendo ser expressas por diferentes tipos de registros. Estas fontes podem ser vistas como documentos. De acordo com Schmidt e Cainelli (2010), no livro Ensinar História, as fontes podem ser primárias e secundárias.

As fontes primárias possuem uma tipologia:

- Fontes materiais: mobiliários, símbolos, instrumentos de trabalho, ruínas, etc.

- Fontes escritas: documentos jurídicos, sentenças, testamentos, inventários, discursos, cartas, textos de imprensa, censos, estatísticas, registros paroquiais, entre outros.

- Fontes visuais: pinturas, caricaturas, fotografias, filmes, vídeos, programas de televisão, etc.

- Fontes orais: entrevistas, gravações, lendas, registros de relatos de viva-voz, programas de rádio, CDs, DVDs (SCHMIDT; CAINELLI, 2010, p. 121).

As fontes secundárias são registros que contêm informações sobre os conteúdos resultantes de uma ou mais elaborações realizadas por diferentes pessoas. Essas fontes nos chegam por pessoas que realizam construções do passado, cujas referências são diferentes testemunhos ou relatos (SCHMIDT; CAINELLI, 2010, p.119).

Tendo em vista que nas fontes primárias encontram-se as fontes visuais, e a pintura histórica é uma fonte, objetiva-se compreender se esta fonte vem sendo tratada como Iconografia Pictórica Histórica nas produções acadêmicas e nas produções destinadas ao público escolar, mais especificamente os livros didáticos, a fim de descobrir se está sendo realizado o diálogo entre estas duas produções e a Iconografia Pictórica Histórica no ensino de história, e se há uma contribuição para a renovação da prática do ensino e da aprendizagem histórica.

A fim de compreender o que significa pintura histórica, e como ela pode ser utilizada como Iconografia Pictórica Histórica, buscou-se uma definição para este termo. Como os autores de referência não citavam claramente o termo de conceito de pintura histórica, procurou-se na internet o que o buscador poderia apontar. 
Segundo consulta no buscador google, dois resultados foram encontrados: o primeiro na página da Wikipédia, e o segundo no site do Itaú cultural. Na Wikipédia a pintura histórica:

[...] é uma forma de arte que pretende registrar algum acontecimento histórico de uma região ou país, muitas vezes exagerando suas glórias ou massacres, e facilmente se tornam símbolos de uma geração e são usadas como iconografias para esses eventos do passado (PINTURA HISTÓRICA, 2015b).

De acordo com o site Itaú cultural, o termo pintura histórica:

[...] se aplica à pintura que representa fatos históricos, cenas mitológicas, literárias e da história religiosa. Em acepção mais estrita, refere-se ao registro pictórico de eventos da história política. Batalhas, cenas de guerra, personagens célebres, fatos e feitos de homens notáveis são descritos em telas de grandes dimensões. Realizadas, em geral, sob encomenda, as pinturas históricas evidenciam um tipo de produção plástica comprometida com a tematização da nação e da política (PINTURA HISTÓRICA, 2015a).

Em se tratando dos trabalhos referenciais, poder-se-ia citar Ulpiano B. de Meneses, Jorge Coli que trabalham com pintura histórica, no entanto não se verifica em específico a definição do termo. Panofsky também trata de pinturas históricas, mas não utiliza claramente o conceito de pintura histórica, mas a iconografia, como "o ramo da história da arte que trata do tema ou mensagem das obras de arte em contraposição à sua forma." (PANOFSKY, 1991, p. 47). Segundo Erwin Panofsky, pela iconografia tem-se a pretensão, a partir da interpretação das imagens, de desvelar a visão de mundo de um grupo social ou de uma cultura.

Para estudo sobre a produção acadêmica, em se tratando da pintura histórica, inicialmente foram consultados: banco de teses e dissertações da Capes e Revistas. As Revistas examinadas: Revista Brasileira de Educação, Revista Brasileira de História, Revista Educar em Revista, Revista eletrônica História Hoje, Revista História \& Ensino-UEL, REDUH-Revista de Educação Histórica. Quanto aos anais dos encontros de congressos consultados: Anais da ANPED, Anais da ANPUH, Anais do ENPEH e Anais do "Perspectivas do Ensino de História". A pesquisa acabou delimitando que os principais resultados encontravam-se nas bases de dados dos anais da ANPUH, Perspectivas do ensino de História e ENPEH. Com isto foi possível organizar a busca a partir dos anos de 1961 a 2013. 
Desta parte de seleção restaram 73 produções acadêmicas que tratavam em específico dos termos: pintura, imagem, iconografia. A partir da leitura destas produções, uma nova seleção de 22 trabalhos das produções acadêmicas foram separados para este estudo, destacando-se os autores: SILVESTRIN, Mônica L. CARNEIRO, Ana Gilka. (1999); BRANCO, Patrícia Martins Castelo (2001); BUENO, João Batista Gonçalves (2001); SCHMIDT, Maria Auxiliadora (2002); CARVALHO, Fábio Garces de. NETO, Ignácio Augusto dos Santos. REIS, Márcio Roberto Coelho dos. (2004); BUSTAMANTE, Regina Maria da Cunha (2004); RIBEIRO, Monike Garcia (2005); BARROS, Ricardo (2005/2007); BANDEIRA, Élcia de Torres (2005); GODOY, Adriana Cristina de. (2006); VARTULI, Silvia M. A. Rachi. SIMAN, Lana de Castro (2007); VALLE, Arthur Gomes (2007); SILVA, Maria da Luz da. (2007); AIRES, José Luciano de Queiroz (2009); AZEVEDO, Vaneska Ferreira de. BANDEIRA Élcia Torres (2009), HERNÁNDEZ, Pedro Alexander Cubas (2009); SILVA, Rosangela de Jesus (2009); JUNIOR, Arnaldo Mertin Szlachta (2011); FERRARI, Anderson (2013); FOCHESATTO, Cyanna Missaglia de. (2013); CECATTO, Adriano (2013).

Estas produções foram organizadas em categorias abertas, axiais e seletivas, que não serão mostradas neste artigo, mas que podem ser consultadas diretamente na dissertação de mestrado de VIEIRA, J.L.L - Cultura Histórica e Cultura Escolar: Diálogos entre a Iconografia Pictórica Histórica e o Ensino de História, Curitiba, 2015.

Sobre a pintura histórica, em termos de produção acadêmica, Frascina (apud PEREIRA, 2002, p. 96), define a pintura histórica como arte detentora de um discurso social que instaurava uma prática social, ou seja, representava um contexto de transformações. Neste sentido,

[...] a pintura não é de modo algum uma concepção abstrata, elevada acima da história, estranha às vicissitudes humanas, às revoluções das ideias e costumes; ela faz parte da consciência social, é um fragmento do espelho em que cada geração olha para si mesma a cada vez e, como tal, deve seguir a sociedade passo a passo, para anotar suas incessantes transformações (FRASCINA apud PEREIRA, 2012, p. 96).

Pereira (2012), delibera que a pintura histórica possuía o papel de ser um aparelho capaz de unir o indivíduo ao todo, colocando-o em atitude de reflexão da 
infinita capacidade humana de associações e experiências, e o movimento entre experiências e ideias.

Segundo o autor, pode-se entender que:

[...] a pintura histórica como produção social sustentava um ritual impresso pela imagem, que procurava instaurar um imaginário para garantir a estabilidade e a ordem, que fundisse a cena com o mundo fora dos quadros. Nesse aspecto, a arte não deveria estar desvinculada da sociedade seja na produção, na circulação e nas etapas de fruição (PEREIRA, 2012, p. 96).

Esta relação estabelecida da reflexão entre experiências e ideias e a representação destas no tempo, enquanto ação de uma sociedade, capaz de instaurar, por meio do imaginário, como uma determinada sociedade expressava a si mesma, tem uma relação especial com a cultura histórica, uma vez que traz elementos que ascendem à memória.

Para o ensino de história, a pintura histórica pode ser uma evidência histórica, uma vez que testemunha o passado.

De acordo com Burke (2004), as imagens permitem que se possa imaginar o passado de uma maneira mais ativa. Sendo assim, elas ocupam o mesmo lugar que os textos e testemunhos orais, pois acabam sendo evidências históricas. "Elas registram atos de testemunho ocular" (BURKE, 2004, p.17). Isto significa que as pinturas são apreendidas como testemunhas do passado, podendo ser testemunhas voluntárias e involuntárias, uma vez que estas imagens foram construídas para serem memória que se deseja deixar como herança de um determinado episódio, ou sobre uma sociedade ou sobre um sujeito e seu determinado grupo social; porém, como relata este autor, são "testemunhas mudas", sendo necessário compreender o que elas desejam relatar.

As imagens em geral acabam sendo criadas com uma finalidade, tendo uma expressão própria, que necessitam de um tratamento próprio, a fim de que transmitam o que elas não expressam declaradamente, mas que se pode ler a partir de aspectos específicos dessa linguagem, seus códigos e como são utilizados pelo artista, criando uma obra única, singular, que pode ser revelada em uma investigação mais aprofundada. Em outras palavras, uma imagem necessita de uma leitura detalhada de natureza artística e histórica; o leitor da obra deve compreender e ter o conhecimento dos seus códigos, para que construa sentidos interpretativos devendo, para isto, estudar a obra com o olhar a partir da escola 
de criação do autor, aspectos como cor, luminosidade, planos, profundidade, elementos da cena, tempo, intencionalidade, informações, representatividade, personagens, espaço, momento de produção, sociedade, interesses, motivação da produção da obra, entre outros.

Burke afirma que "para utilizar a evidência de imagens de forma segura, e de modo eficaz, é necessário, como é o caso de outros tipos de fonte, estar consciente das suas fragilidades" (BURKE, 2004, p.18). Isto significa dizer que toda imagem pode servir de evidência histórica desde que seja dado o trato merecido, ou seja, devem ser realizadas as perguntas próprias que farão que ela se demonstre enquanto evidência.

A pintura histórica, enquanto representação de um passado, pode ser uma evidência porém, por ser um gênero artístico, sofre alterações no decorrer do tempo, que devem ser avaliadas e analisadas conforme o tempo específico, ou seja, a época representada, devendo ser vista como um sistema de convenções que sofre alterações lentas no tempo, mas que vão evoluindo e onde estas convenções têm um propósito inerente.

Neste sentido, ao se olhar uma pintura histórica é preciso ressaltar que ela pode ser utilizada como uma evidência histórica, mas para isto é necessário observar alguns pontos. De acordo com Burke (2004, p. 37):

- A arte pode fornecer evidência para aspectos da realidade social que muitas vezes os textos passam por alto, pelos menos em alguns lugares e épocas.

- A arte da representação é menos realista e distorce a realidade social mais do que refleti-la, de tal forma que historiadores não levem em consideração a variedade das intenções do pintores (sem falar nos patronos e clientes) podem chegar a uma interpretação seriamente equivocada.

- Entretanto, o processo de distorção, é ele próprio, evidência de fenômenos que muitos historiadores desejam estudar, tais como mentalidades, ideologias e identidades. A imagem material ou literal é uma boa evidência da "imagem mental" ou metafórica do eu ou dos outros.

Burke chama a atenção para o tratamento que se deve dar ao observar uma pintura histórica. Se for observada com o olhar que precisa para as descobertas, ela pode se tornar evidência, uma vez que permite investigar o que cada ponto está representado e o que não se pode enxergar num primeiro momento, mas que 
está expresso para responder perguntas em torno da representação de uma sociedade. Mesmo trazendo uma imagem distorcida, é necessário compreender que aquela pintura histórica possui intencionalidades, tanto de pintores como de quem encomendou a obra e, muitas vezes, a imagem não representa tudo o que está escondido por detrás da obra, porém expressa coisas que muitas vezes são descobertas sem que houvesse uma finalidade para tal, revelando o inimaginado, ou aguçando a curiosidade para pesquisar sobre mentalidades, ideologias e identidades.

Burke (2004) mostra que o trato com as imagens deve seguir alguns princípios entre eles:

[...] as imagens não dão acesso ao mundo social diretamente, mas sim a visões contemporâneas daquele mundo, devendo os historiadores não esquecer as tendências opostas dos produtores de imagens para idealizar e satirizar o mundo que representam. 0 testemunho das imagens deve ser colocado em uma série de contextos culturais, políticos, econômicos, em um determinado tempo e lugar bem como os interesses do patrocinador e do artista e a pretendida função da imagem. Também há que se relacionar que uma série de imagens pode trazer testemunho mais confiável do que imagens individuais e que o historiador deve observar detalhes pequenos, mas significativos, incluindo ausências significativas - usando-as como pistas para informações que os produtores de imagens não sabiam que eles sabiam, ou para suposições que eles não estavam conscientes de possuir (BURKE, 2004, p.237-238).

Para Burke uma imagem pode revelar coisas que, às vezes, nem o pintor sabia da existência ao fazer, às vezes tinha esta consciência também, porém, em muitos casos, isto só aparece se for investigado. A pintura histórica tem um tratamento específico de análise que deve considerar o conteúdo substantivo da história, ou seja, o que se desejou representar dentro de um período histórico, bem como as intencionalidades do autor e também as questões de natureza específica da arte enquanto reprodução artística.

Quando se fala em pintura histórica é importante destacar que todas as pinturas foram criadas em um determinado tempo e espaço, e são representativas destes. Para que seja histórica, ela deve estar relacionada a uma sociedade e uma determinada época, explicitando um sentido e um significado para a história. Nesta ótica, toda pintura é histórica em si, mas nem toda a pintura representa um 
conteúdo especificamente histórico e tem efeito continuado sobre a cultura de uma sociedade.

As pinturas são históricas mas, muitas vezes, não são trabalhadas com o cuidado necessário para que sejam uma fonte de estudo. Deve ser dado a elas um tratamento específico, com perguntas da natureza do conteúdo substantivo histórico, bem como perguntas específicas da natureza artística, o que será melhor explicado no decorrer deste texto.

De início é importante destacar que a Iconografia Pictórica Histórica é um conceito que perpassa a imagem pictórica ou a pintura histórica, pois está vinculada aos elementos e dimensões da cultura histórica. Para compreender isto, torna-se preciso definir cultura.

Segundo Rüsen, por cultura pode-se entender a relação que o ser humano possui, com seu mundo e consigo mesmo, gerando interpretações. Estas relações fazem com que o homem consiga expressar sua cultura histórica. "A cultura histórica faz parte da vida humana, sendo a percepção, interpretação, orientação e o estabelecimento de uma finalidade, que toma o tempo como fator determinante da vida humana." (RÜSEN, 2009a, p. 6).

É por intermédio da cultura histórica que ocorre a memória histórica, exercida, por sua vez, pela consciência histórica, ou seja, a relação entre a interpretação do passado, a compreensão do presente e a perspectiva do futuro. Em outras palavras, poder-se-ia dizer que a consciência histórica é a expressão da cultura histórica. A consciência histórica possui condição de ser elaborada a partir de interpretações, e a Iconografia Pictórica Histórica aparece como uma das formas que se pode chegar a interpretações sobre o passado e relações.

Por ser um elemento de narrativa do passado, a Iconografia Pictórica Histórica, almeja por meio da estética, conduzir a uma memória de interpretação do acontecimento ou fato representado, sendo a pintura histórica, enquanto Iconografia Pictórica Histórica, capaz de relembrar fatos passados, mobilizar lembranças, recuperar períodos, trazer o passado tornando-o presente, atribuindo sentidos para o ser humano.

Como a Iconografia Pictórica Histórica expressa sentidos consegue, por meio da representação do passado, conceder que o presente seja relacionado a ele, constituindo-se elemento de mutação, ou seja, cada vez que se interpreta uma 
pintura ela pode constituir-se de forma diferente a cada olhar, haja vista que a interpretação é pessoal e subjetiva. As perguntas feitas à pintura serão sempre diferentes, portanto, organizam pensamentos diversos em torno de um mesmo assunto.

No entanto, para que isto aconteça é preciso o questionamento da Iconografia Pictórica Histórica, a contextualização e a investigação, com a finalidade de buscar o sentido e a plausibilidade do fato histórico, ou seja, conseguir, por meio de evidências históricas, que seja aproximado o real (no sentido de ter existido) - ao representado, podendo ser esta representação a partir da visão de escola de cada artista que representou, ou seja, do impressionismo, do cubismo, do abstracionismo, do realismo, entre outros. A evidência constitui a base da construção do conhecimento histórico, o fundamento da inferência, da argumentação. Uma evidência somente poderá ser considerada como tal se estiver no movimento de ação do sujeito, ou seja, se se permitir inferir, induzir e deduzir sobre o que se deseja pesquisar.

Hilary Cooper, afirma que a evidência histórica está relacionada a ação. Esta autora faz referência ao historiador Collingwood (1939) para definir evidência:

Evidência histórica significa se isso é um artefato, um prédio, um quadro ou algo escrito. É um resultado de uma ação. Uma ação é o resultado de um pensamento racional. O pensamento racional tem suas raízes em sentimento e imaginação. Sentimentos e pensamentos só continuam a existir à medida que eles são representados na ação, na evidência (COOPER, 2012, p. 24)

Para Ashby, o conceito de evidência histórica se relaciona às fontes. Neste sentido a autora reporta que a investigação histórica ocupa um aspecto relevante da história escolar. O conceito de evidência histórica deve ser desenvolvido pela exploração da natureza das questões históricas, e a forma pela qual se organizam os parâmetros para o tipo de evidência nos quais as respostas a essas questões possam estar baseadas, e na habilidade da evidência em sustentar o peso de qualquer afirmação que seja feita (ASHBY, 2006, p.156).

Ashby propõe uma relação de evidência entre as fontes históricas que podem ser entendidas "a partir de um conceito de que foi a sociedade quem as produziu, e as afirmações sobre o passado que elas apoiam" (ASHBY, 2006, p.155). 
Pensando no conceito destas duas autoras, a Iconografia Pictórica Histórica pode revelar evidências históricas e direcionar as construções de pensamentos que permitam encaminhar a formação da consciência histórica, que é a expressão da cultura histórica. Neste sentido, a evidência é a interpretação da fonte, é a fonte explicada, decodificada e comentada.

Rüsen (2009a) aponta três dimensões da cultura histórica para a atividade memorativa da consciência histórica, sendo elas: estética, política e cognitiva.

\begin{abstract}
Dimensão política: relacionada com a legitimação de certa ordem política, primeiramente com as relações de poder. A consciência histórica as inscreve, por assim dizer, nas concepções de identidade dos atores políticos, nas construções e concepções do eu e do nós, através de narrativas mestras que respondem a questão da identidade. Não há ordem política que não requeira legitimação histórica. Dimensão estética: relacionada com eficácia psicológica das interpretações históricas, ou com a parte de seus conteúdos que afetam os sentidos humanos. Uma forte orientação precisa sempre envolver os sentidos [...] O conhecimento histórico precisa empregar modelos narrativos para se tornar um discurso.

Dimensão cognitiva: relacionada com eventos passados significativos para o presente e seu futuro. Sem o elemento do conhecimento, a lembrança do passado não pode efetivamente ser introduzida nos discursos relacionados com a interpretação das experiências temporais correntes (RÜSEN, 2009b, p.172-173).
\end{abstract}

De acordo com Rüsen (2009a), na dimensão estética as recordações históricas aparecem em forma de criações artísticas. Muitas vezes essas criações representam algo, mas a construção de sentido e significado parece estar longe de uma verdadeira memória histórica, pois são produtos culturais. Neste sentido, cabe a cultura histórica colocar o estético no histórico, a fim de que haja um trabalho memorativo que conduza a uma consciência histórica, pois se for feito o contrário, as criações artísticas podem mostrar um passado morto e irreal, se desvencilhar do histórico e não conduzir a interpretações e experiências.

É importante lembrar que a estética é imaginativa e, por isso, pode levar a, simplesmente, uma representação sem relação com a experiência, a qual acaba não tendo valor para o conhecimento histórico, ou encaminhar para uma experiência do passado com relações que se pode estabelecer no presente e perspectivar um futuro. Conforme Rüsen, 
[...] o poder imaginativo da estética é histórica, enquanto trabalhada com a experiência passada, ou melhor, as atualizações; mas não é quando se transforma esta experiência histórica em uma criação puramente artificial, ou seja, aliviado da experiência (RÜSEN, 2009a, p.18, tradução da autora) ${ }^{2}$.

No que diz respeito a dimensão política, Rüsen (2009a) afirma que ela se baseia em formas de domínio e necessita de um consentimento dos envolvidos. Neste sentido, as relações de poder se apresentam de forma duradoura no tempo e a memorização histórica tem o poder de legitimação.

A legitimidade, segundo Rüsen (2009a), seria a capacidade de domínio de receber consentimento, e a memória histórica um meio deste consentimento. $A$ legitimidade constrói o domínio político mentalmente, que se entrelaça com as construções de sentido da consciência histórica, servindo de orientação cultural na vida prática e, portanto, atingindo a identidade histórica a qual, por sua vez, é construída no meio de poder e domínio do ser humano consigo mesmo e com o outro.

Ao que se refere a dimensão cognitiva, Rüsen afirma que "se trata do princípio de coerência de conteúdo, que se refere a confiabilidade da experiência histórica e ao alcance das normas que se utilizam para sua interpretação ${ }^{3 \prime}$ (RÜSEN,2009a, p.20, tradução da autora).

A relação cognitiva se propaga nas ciências históricas por meio de regras metodológicas das atividades da consciência histórica a fim de orientar, compreender, dirigir, organizar, e interpretar, se há consistência no conteúdo, ou seja, se a experiência histórica é confiável.

Na perspectiva de Rüsen (2009a), o conceito de cultura histórica e suas dimensões, indicam a possibilidade de um diálogo com as maneiras pelas quais a cultura escolar se apropriou da Iconografia Pictórica Histórica, particularmente nos elementos produzidos e destinados ao uso dos processos de escolarização.

$\mathrm{Na}$ cultura escolar, as três dimensões da cultura histórica, propostas por Rüsen, estão presentes e, nesse sentido, a pintura histórica precisa ser olhada

\footnotetext{
2 La fuerza imaginativa de lo estético es histórica mientras trabaja com la experiência del passado, o mejor, la pone al día; pero no lo es cuando transforma esta experiência histórica em uma creación puramente artificial, es decir, revelada de la experiência (RÜSEN, 2009a, p. 18).

3 Se trata del principio de coherencia de contenido, que se refiere a la fiabilidade de la experiência histórica y al alcance de las normas que se utilizan para su interpretación (RÜSEN, 2009a, p. 20).
} 
como um artefato da cultura histórica, por isso deve ser vista como Iconografia Pictórica Histórica. Um professor precisa entender como aquela determinada pintura histórica esteticiza o passado, ou seja, como o passado é mostrado em uma representação na perspectiva do realismo, impressionismo, surrealismo, modernismo, romantismo, classicismo, neoclassicismo ou outros estilos (pois cada artista tem uma identidade própria dentro das "escolas") a fim de saber o porquê o autor utilizou-se desta forma para mostrar o passado. Quando o professor consegue compreender este processo e mostrar para o aluno que a obra contempla as diferentes dimensões da cultura histórica (política, estética, cognitiva), ele alcança o entendimento do estudante para a forma com que o passado foi esteticizado e necessita ser revelado na Iconografia Pictórica Histórica.

No que se refere a dimensão política, na cultura escolar, trata-se de o professor compreender como o passado está politicamente representado na obra. Isto significa que é preciso que o professor perceba e trabalhe as questões de poder que estão ali representadas na pintura histórica, enquanto Iconografia Pictórica Histórica. Se está se estudando uma pintura histórica de Pedro Américo, por exemplo, Independência ou Morte (1888), é necessário entender o porquê esta obra foi encomendada, qual a finalidade, o que desejava representar e o que ou a quem queria convencer. É necessário a construção e organização de uma identidade histórica e, para isto, é preciso poder e domínio, convencimento dos envolvidos. A dimensão política permite compreender vários aspectos que não se mostram num primeiro momento apenas na contemplação da obra, a Iconografia Pictórica Histórica revela estes aspectos políticos quando é realizado o tratamento devido, ou seja, as questões pertinentes.

Quanto a questão da cognição, na cultura escolar, o professor necessita compreender como aquele elemento da cultura histórica foi didatizado, ou seja, verificar de que forma a pintura histórica foi trabalhada didaticamente nos livros didáticos. É preciso que o professor, ao se defrontar com uma pintura histórica no livro didático, possa perceber a forma com a qual o autor trabalhou e de que maneira está encaminhando o aluno para ele pense sobre determinado conteúdo.

Neste sentido, se o professor olhar o livro didático encontrará atividades propostas pelos autores como: caracterize a pintura histórica; descreva os elementos da pintura histórica e relacione; defina o episódio histórico que está 
representado na pintura; entre outros, o que poderá conduzir a um tipo de pensamento. Ao professor cabe avaliar essas atividades e o tratamento da pintura histórica nos livros, para ver se contribuem para o conhecimento do estudante. Num trabalho com pinturas históricas a dimensão cognitiva só aparecerá se a pintura histórica for vista como Iconografia Pictórica Histórica, ou seja, fonte como evidência.

Desta maneira, as três dimensões da cultura histórica segundo Rüsen, quando inseridas na cultura escolar permitiram pensar que a pintura histórica que aparece nos livros didáticos, ou em outros meios de representação, não pode ser tratada apenas como uma imagem de uma obra de arte, uma imagem de uma pintura de um acontecimento histórico. Para que tenha sentido e significado para o ensino e aprendizagem histórica, ela deve ser tratada como Iconografia Pictórica Histórica.

Os estudos na perspectiva da cultura histórica, nas dimensões da cultura histórica de Rüsen, e no conceito de evidência histórica de Cooper e Ashby permitiram construir uma definição para a Iconografia Pictórica Histórica, dentro do campo da teoria da consciência histórica.

Neste sentido, ficou assim definida: Iconografia Pictórica Histórica é a leitura e interpretação da pintura histórica como artefato da cultura histórica, podendo tornar-se uma fonte, com um tratamento específico a partir dos elementos estético, político e cognitivos da cultura histórica que revelem evidências históricas, trazendo contribuições para a formação da consciência histórica.

A Iconografia Pictórica Histórica deve proporcionar na cultura escolar o tratamento da pintura histórica como uma fonte, um artefato da cultura histórica que forneça indicações sobre a época que pertenceu, a partir de perguntas que se referem a natureza específica da pintura e a natureza do conteúdo substantivo histórico: o que, para quem, por que, de que forma, com que finalidade, escola em que foi produzida, dimensão, local, entre outros. Estas perguntas devem estar relacionadas às dimensões da cultura histórica: o estético, o político e o cognitivo, devendo, a partir destes questionamentos e investigações, levantar evidências para o estudo e formulação de pensamentos que direcionem a elaboração de uma consciência histórica. 
Neste sentido, a pintura histórica pode trazer informações que não estão expressos declaradamente, mas que podem conduzir a um processo de rememoração. Isto denota que a pintura histórica pode servir para tornar à memória os fatos que aconteceram, e que possibilitam a investigação, trazendo plausibilidade para as representações contidas numa obra, bem como possibilidades de interpretações.

\section{Compreendendo a Iconografia Pictórica Histórica como elemento da cultura histórica}

Entenda-se que a Iconografia Pictórica Histórica potencializa visões de mundo e com elas podem ser exploradas a memória de uma sociedade. O que confere dizer que a Iconografia Pictórica Histórica faz parte de uma sociedade e, portanto, constitui-se em elemento da cultura histórica. Rüsen (2009a), afirma que a cultura pode ser entendida como a "relação ativa e passiva do homem com seu mundo e consigo mesmo, na qual o mundo e ele mesmo devem ser interpretados a fim de que se possa viver com e no mundo." (RÜSEN,2009a, p. 5).

Para este autor, a cultura está revestida da história da sociedade que, por fazer parte da vida humana, tem como seu principal fator o tempo que determina as ações as quais necessitam de uma interpretação para gerar sentido.

É na cultura histórica que ocorre a memória histórica a qual, por sua vez, é exercida pela consciência histórica, ou seja, a relação entre a interpretação do passado, a compreensão do presente e a perspectiva do futuro. A Iconografia Pictórica Histórica pode favorecer a formação da consciência histórica por ser um elemento de narrativa do passado, um elemento da cultura histórica, um artefato da cultura histórica que consegue, por meio da estética, conduzir a um tipo de memória de interpretação do acontecimento ou fato representado.

A pintura histórica, vista como Iconografia Pictórica Histórica, possui sentido de representação. O passado ao ser reportado ao presente constitui-se elemento de mutação, sendo preciso a investigação, a problematização e a contextualização, a fim de buscar o sentido e a plausibilidade do fato histórico. 
Desta forma, quando se propõe a possibilidade de uso da Iconografia Pictórica Histórica como fonte nas aulas de história, levando em consideração a apreensão destas fontes como processos oriundos das dimensões cognitivas, estéticas e políticas da cultura histórica, propõe-se, ao mesmo tempo, que o passado representado, por meio da pintura e esteticizado nas imagens, seja levado para a cultura escolar e transforme-se em elemento de aprendizagem histórica. Entende-se o conceito de cultura escolar como:

[...] o conjunto dos conteúdos cognitivos e simbólicos que, selecionados, organizados, "normalizados" "rotinizados", sob o efeito dos imperativos da didatização, constituem habitualmente o objeto de uma transmissão deliberada no contexto das escolas (FORQUIN,1993, p.167).

Assim, pode-se entender que o passado esteticizado por meio da Iconografia Pictórica Histórica, expresso na cultura histórica, possa ser transferido para a cultura escolar, ou seja, para a escola, a partir, por exemplo, de sua presença nos manuais didáticos, considerados como um dos elementos da cultura escolar. Portanto, os manuais didáticos são considerados recursos que tornam acessível o uso da Iconografia Pictórica Histórica como fonte, a fim de que esta seja levada a interpretações no ensino de história as quais possibilitam aprendizagem histórica e a formação da consciência histórica.

A Iconografia Pictórica Histórica pode ser um elemento de narrativa do passado porque consegue, por meio da estética, conduzir a uma memória de interpretação do acontecimento ou fato representado. Para isto, é necessário olhar com os olhos do pintor e compreender por que aquela pintura foi representada daquela forma, a partir de que perspectiva é que expressa o passado, em função de que formação escolar se representa, se é a partir do realismo, do cubismo, do impressionismo, entre outros, pois há uma forma específica do movimento da época para representar tal período histórico.

É necessário a compreensão da forma que a pintura histórica consegue esteticizar o passado, ou seja, ao mobilizar uma lembrança de uma determinada época, é possível retornar ao passado tornando-o presente, e a narrativa constitui, neste momento, a permanência de tornar presente o passado e mediar a expectativa futura. Poder-se-ia dizer ser a memória histórica o fio condutor que 
levaria o sujeito à sua identidade e realidade, de acordo com seu tempo, e a Iconografia Pictórica Histórica serviria para este transportar até a consciência histórica, uma vez que consegue tratar a pintura histórica com o devido tratamento, a partir da especificidade da obra, no sentido de organizar uma leitura e interpretação pelos aspectos históricos e particulares da pintura.

Conforme Peter Burke (2004), a imagem contida na representação pictórica é um recurso para se chegar à interpretação de um momento histórico, ela não é o real, todavia "serve para desconstrução de ideias, mentalidades, ideologias e identidades e podem testemunhar aquilo que não pode ser colocado em palavras" (BURKE, 2004, p. 38).

Contudo, mesmo não sendo o real, a Iconografia Pictórica Histórica, direciona a busca pelo real e, quando o passado é esteticizado, acaba se manifestando também na cultura escolar. A cultura escolar é a seleção dos componentes essenciais a serem ensinados no âmbito escolar. Segundo Forquin (1993, p. 14), "a cultura é o conteúdo substancial da educação, sua fonte e sua justificação última, é na educação que a cultura se transmite e se perpetua."

Pode-se dizer que se a cultura é tudo o que antecede ao ser humano e the é próprio, ou seja, o homem já nasce em uma cultura e é na escola que se processam os saberes, regras, hábitos, valores, conteúdos, e toda a experiência humana, e também na escola que ela se eterniza, a cultura escolar então pode ser definida como a escolha selecionada dos conteúdos de acordo com os interesses sócio-político-econômicos. Estes conteúdos selecionados direcionam o trabalho de acordo com as linhas de interesse.

No caso do ensino de história, a cultura escolar pode ser manifesta por um interesse político, de poder; expresso através das representações temporais de uma sociedade, compondo-se em um passado esteticizado. A forma como esta representação do passado esteticizado se expressa na cultura escolar é através dos recursos didáticos que fazem parte desta cultura para a manifestação do ensino e aprendizagem da história, sendo um dos principais recursos, os manuais didáticos. Com o seu uso em sala e, consequentemente, as fontes existentes neste recurso, pode-se explorar a construção da aprendizagem histórica, do pensamento histórico e, por conseguinte, da consciência histórica. 
Quando se falou que a Iconografia Pictórica Histórica presente nos manuais didáticos pode se constituir elemento importante para a construção do pensamento histórico, uma vez que remete a uma memória, a qual por sua vez é elemento de constituição do passado, dada pela cultura histórica, pretendeu-se deixar claro que a relação do manual didático com a fonte Iconografia Pictórica Histórica pode ascender a um processo de memoração, e retornar a lembranças nesta relação intimamente ligada ao processo de ir e vir, trazendo o passado ao presente, e proporcionando sensações e sentidos que geram significados e produzem pensamentos. Estas sensações e sentidos, dados pela imagem da pintura histórica, se forem trabalhados como Iconografia Pictórica Histórica, podem conduzir a pensamentos históricos que se manifestam por meio da consciência histórica.

\section{Diálogo entre Iconografia Pictórica Histórica e o ensino de história}

De acordo com Rüsen (2010, p. 58), a consciência histórica acaba sendo processada quando ocorre relações entre as experiências e as interpretações do tempo. Desta maneira, quando foi anunciada a possibilidade de um diálogo entre a Iconografia Pictórica Histórica e o ensino de história, pretendeu-se que ela fosse responsável por operações mentais, transformando os pensamentos em aprendizagem histórica e, portanto, demonstrando o quanto o ensino e aprendizagem histórica podem ganhar com o uso da Iconografia Pictórica Histórica.

Para se compreender o que significa aprendizagem histórica, é preciso entender o que é história. Para dar acepção ao conceito história, as correntes historiográficas possuem inúmeras definições, entretanto, neste trabalho, a intenção foi buscar um significado para a história tendo em vista o campo de pesquisa da Educação Histórica.

A Educação Histórica é, segundo Schmidt e Barca (2009), um campo de estudo e investigação que tem como preocupação o desenvolvimento do pensamento histórico e a formação da consciência histórica do ser humano.

Neste sentido, parte do princípio que o estudo da história não se restringe a compreensão exclusiva do passado, mas objetiva múltiplas temporalidades, ou 
seja, a relação das ações humanas no tempo por meio do passado, presente e futuro, gerando, assim, multiperspectivas nas experiências históricas dos sujeitos que são, ao mesmo tempo, agentes. Desta forma, a Educação Histórica tem como foco de suas investigações as fontes, as estratégias de aprendizagem da história e os conhecimentos prévios do ser humano em torno da história.

Segundo Rüsen, a história pode ser compreendida como:

[...] a realidade concreta da vida dos homens efetivada no agir; a reflexão racional de cada um sobre sua experiência no tempo; o ramo científico de apreensão, descrição, entendimento e explicação do agir humano no tempo; o teor articulado da narrativa constante dos livros e outros produtos análogos (um conteúdo); a soma de toda presença humana no tempo e espaço desde quando não sabemos até quando também não dominamos (um processo) (RÜSEN, 2012, p.9-10).

O autor aponta formas diversas de assumir o que é a história em si, tratando-a como realidade, reflexão, entendimento, explicação, conteúdo, presença humana no tempo e espaço, o agir. Explicita que todos estes elementos constituem a história e, para que ela realmente seja significativa, o ser humano deve estar inserido em suas ações transformando-as em narrativas do presente e do passado. Desta forma, a história é o que conduz a diversidade do cotidiano humano. Ela é a responsável por transmitir as pegadas deixadas pela humanidade e a construir os caminhos a serem trilhados, no vaivém do passado ao presente, e na proposição do que será o futuro, o ser humano transita entre a experiência e a reflexão sobre suas ações, constituindo o que viveu, a sua cultura, em um aprendizado para a vida. Neste sentido, a aprendizagem histórica ocorre quando há reflexão sobre algo que se deseja alcançar em relação ao conhecimento. $\mathrm{O}$ ato de buscar, instigar, especular, pode ser codificado como uma carência. Para Rüsen, a carência de orientação, sentida pelo indivíduo na experiência e na reflexão de seu tempo, o conduz a buscar (e, se não encontrar, pelo menos estabelecer) horizontes e perspectivas de ação. A carência de orientação é um diagnóstico presente. A busca se faz no estoque da experiência passada (histórica) presente no dia atual, de modo a viabilizar a ação a ser empreendida (futuro). A síntese mental, realizada pelo agente, se dá de forma narrativa. Ele anuncia a experiência 
vivida, descreve seus elementos, analisa seus componentes, articula seu sentido, enuncia suas metas (RÜSEN, 2012, p. 10).

Rüsen propõe que é a carência de orientação que direciona a busca do passado no presente e suas experiências que conduzem para as respostas que são capazes de empreender ações futuras. A carência é a falta de orientação que acaba gerando o interesse. Neste sentido, segundo Schmidt (2014), as carências de orientação são provocadas pelo sofrimento ou incapacidade imobilizadora de agir do passado no presente, e quando ocorre esta carência é que ela torna-se pensamento que acaba sendo expresso e manifesto na consciência histórica. ${ }^{4}$

Desta forma, pode-se admitir que a consciência histórica é o pensamento que se instaurou, pois, uma vez que existe uma carência de orientação, é preciso recorrer a história para satisfazê-la. Contudo, ao buscar na história esta resposta, torna-se primordial a reflexão sobre os fundamentos da ciência da história que são os interesses do passado no presente, gerados pelas carências, e interpretados, de forma que se possa chegar a objetivos finais. Isto requer que os interesses abordados pela teoria da história tenham relação direta com a vida cotidiana, a fim de produzir sentido e significados, sendo que o pensamento histórico se processa na compreensão do presente, na projeção do futuro e na recuperação do passado, o que confere dizer que, quando há uma carência inicial de orientação, a historiografia se apropria dela e gera respostas que se consolidam na consciência histórica.

Nesta ótica, Rüsen insere que ao sentir necessidade de reflexão sobre algo e buscar descobrir os vestígios ou respostas sobre ele, é possível consultar o passado numa visão de presente que acaba por se construir expectativas de futuro. Literalmente é o passado no presente, perspectivando o futuro. Essa busca de compreensão do passado e da história, relacionando presente e futuro, constitui-se em uma aprendizagem.

Por aprendizagem pode-se designar todo o ato que passa pela experiência humana. Neste aspecto, a experiência é composta por ações realizadas pelo homem durante a história. De acordo com a aprendizagem histórica, ela vai muito além do simples conceito do instruir-se. Rüsen (2012, p. 11), assinala que a

\footnotetext{
4 Anotação em aula proferida no $1^{\circ}$ semestre de 2014, pela professora Doutora Maria Auxiliadora Moreira dos Santos Schmitd - UFPR.
} 
aprendizagem da história passa pela experiência, orientação e interpretação, e direciona que ela é constante, ou seja, o ser humano está sujeito a transformações, mudanças e correções que acontecem diariamente ou no decorrer do tempo, as quais estão relacionadas as ações presente-passado e presentefuturo, devendo sempre analisar, descobrir, criticar, organizar os modelos já postos pela sociedade e suas interpretações, de maneira a construir novos olhares para aquilo que já se faz consolidado.

Neste sentido, o aprendizado histórico pode ser definido como o trabalho de efetivar, realizar, comprovar, confirmar, diferenciar ou concretizar a competência narrativa. A aprendizagem histórica é um processo básico e fundamental em que toda a aprendizagem organizada baseia-se nesta natureza, e define todas as possibilidades e limites. Tais considerações levaram à mudança da didática da história, que tem a consciência histórica como base de todo o ensino e aprendizagem da história. Nessa mudança pode-se associar e explicar a consciência histórica como teoria da aprendizagem (RÜSEN, 2012, p. 74).

Rüsen chama a atenção ao fato de que a aprendizagem histórica baseia-se na natureza do aprender, isto requer a transformação das informações obtidas em conhecimentos, voltados num processo mental que a consciência processa a fim de concluir ideias complexas que se combinam gerando a aprendizagem histórica.

Segundo Schmidt e Cainelli (2010, p. 66), quando advém a apropriação das ideias históricas cada vez mais complexas, por meio da modificação das informações em conhecimentos, ocorre a aprendizagem histórica de maneira significativa.

De acordo com as autoras, existem pressupostos para uma aprendizagem histórica ser expressiva. O primeiro deles é que a história é sempre uma interpretação; neste sentido, o que se coloca em discussão é a ideia de uma história única, verdadeira e universal. A história deve ser multiperspectivada, ou seja, pode ser contada de vários prismas, anulando a antiga visão de uma história exclusiva. O segundo é que novas correntes historiográficas trouxeram o retorno da narrativa, isto significou um avanço no sentido de compreensão de uma perspectiva mais específica voltada à construção de argumentos históricos explicativos, com análise da ação dos agentes e do contexto onde ocorre a ação, permitindo, assim, várias interpretações, ressignificações do presente e 
orientações que permitam a construção de atos e feitos para a vida e realidade social.

As autoras pontuam que uma das finalidades da aprendizagem histórica é a formação da consciência histórica, ou seja, a realidade a partir do que a história é e a sua real necessidade. De acordo com Rüsen (2012), a consciência histórica pode ser definida como um processo mental, como um conjunto de operações da consciência (emocional, cognitivo e pragmático), que diferem de outros conjuntos conceitualmente claros e que, em sua especificidade, podem ser explicitados (RÜSEN, 2012, p. 74).

Rüsen deixa claro ser a consciência histórica algo que faz parte do humano quando afirma que ela é um conjunto de operações mentais. Isto leva a admitir que todos nascem com capacidade de desenvolvimento da consciência histórica, a partir das operações mentais realizadas pelo sujeito enquanto agente. Nesta ótica, é viável dizer que a consciência histórica é formada a partir da aprendizagem histórica, pelas ações que o pensamento histórico realizou. A aprendizagem histórica propõe o desenvolvimento da capacidade de orientação temporal, ou seja, passado e presente, de maneira que torne-se significativo. Por estar na relação tempo, a aprendizagem histórica é um movimento contínuo e dinâmico, o que pressupõe que a experiência seja uma dimensão importante para a transição. De acordo com Schmidt e Cainelli, a experiência é uma dimensão importante da aprendizagem histórica, porque aprender história é crescer na experiência obtida no passado humano, desenvolvendo também a capacidade de se abrir e de selecionar novas experiências que sejam verdadeiramente históricas. Essa perspectiva da aprendizagem histórica pressupõe o fato de que se compreenda o passado como histórico, como um tempo qualitativamente diferente do presente (SCHMIDT; CAINELLI, 2010, p. 71).

Portanto, a experiência define que o passado é qualitativamente diferente do tempo presente, um relaciona-se ao outro, porém não toma o seu lugar, sendo necessário que haja uma interpretação desta experiência para torná-la significativa para a aprendizagem histórica.

A interpretação é outra dimensão da aprendizagem histórica, Schmidt e Cainelli (2010), afirmam que ela contribui no sentido de atribuir significado aos fatos históricos, proporcionando meios de agregar vários tipos de conhecimentos 
e experiências. Neste sentido, a interpretação contribui para que seja desmistificado que exista uma verdade histórica única. Desta forma, ao atribuir que há formas variadas de cognição, abre-se perspectivas de que o conhecimento histórico pode ser alterado de acordo com o inquérito dispensado a ele ou referente a argumentação que Ihe foi proposta.

Outra dimensão da aprendizagem histórica é a orientação, que deve ser situada no tempo. Segundo as autoras Schmidt e Cainelli, aprender história é sempre desenvolver a capacidade para se situar no tempo, relacionando o passado com o presente e o futuro. Isto porque os elementos históricos estão sempre presentes no autoconhecimento das pessoas e no significado que elas dão ao mundo (SCHMIDT; CAINELLI, 2010, p. 71).

De acordo com a dimensão da orientação, o ser humano para aprender historicamente necessita organizar-se no tempo, visto que é ele que atribui o sentido do passado no presente, e quando há uma relação entre estas temporalidades é admissível perspectivar ações futuras.

Para a aprendizagem histórica as três dimensões - experiência, orientação e interpretação - acabam se relacionando intrinsecamente, uma vez que não é plausível conceber que haja experiência sem sentido, orientação sem vivência, ou mesmo a falta de interpretação para gerar diferentes acepções aos fatos existentes - novos olhares sobre o que já está posto como fato.

O que se conclui é que no intuito de propiciar a aprendizagem histórica nos jovens estudantes e, consequentemente, elaborar uma consciência histórica mais crítica, pesquisadores trabalham para que as fontes históricas se transformem em um instrumento no qual professores possam utilizá-las metodologicamente e conseguir resultados positivos.

Algumas produções na área de história demonstram uma maior apreensão com a análise historiográfica das fontes históricas, em específico com a Iconografia Pictórica Histórica. Outros trabalhos, por sua vez, pretendem apresentar procedimentos e técnicas adequadas para o uso da pintura histórica como recurso, ambicionando uma forma de averiguação que demonstre novas expectativas ou probabilidades em relação ao uso da imagem. 


\section{Considerações finais}

Os resultados desta pesquisa puderam esclarecer como a Iconografia Pictórica Histórica consegue relacionar-se ao ensino da história. A Iconografia Pictórica Histórica foi definida tomando por base conceitos de evidência de alguns autores da área, haja vista que para a Educação Histórica não havia um conceito que pudesse representar sua importância. Também foi considerada como expressão de uma cultura histórica de uma sociedade e, portanto, um elemento capaz de ascender a aprendizagem histórica, pois possui sentido de representação, em que o passado, ao ser reportado ao presente, constitui-se elemento de mutação, necessitando, para isto, da investigação, da problematização e da contextualização. Para o ensino de história, a Iconografia Pictórica Histórica passa a ser vista com o sentido de evidência. Desta forma, o uso da Iconografia Pictórica Histórica como fonte nas aulas de história, provenientes da cultura histórica (dimensões cognitivas, estéticas e políticas), propõe que o passado, representado por meio da pintura e esteticizado nas imagens, seja levado para a cultura escolar e transforme-se em elemento de aprendizagem histórica. Portanto, na cultura escolar a pintura histórica precisa ser vista como um artefato da cultura histórica, ou seja, como Iconografia Pictórica Histórica para o desenvolvimento da consciência histórica. O estudo também proporcionou uma análise de produções acadêmicas e escolares que serão abordadas num próximo artigo.

\section{Referências}

ANPED - ASSOCIAÇÃO NACIONAL DE PÓS-GRADUAÇÃO E PESQUISA EM EDUCAÇÃO. Biblioteca. Disponível em <http://www.anped.org.br/anped/biblioteca-anped/anais>. Acesso em: 14 jun. 2014.

ANPED - ASSOCIAÇÃO NACIONAL DE PÓS-GRADUAÇÃO E PESQUISA EM EDUCAÇÃO. RBE. Disponível em: <http://www.anped.org.br/rbe/edicoes/ numeros-anteriores>. Acesso em:2 ago. 2014.

ANPUH - ASSOCIAÇÃO NACIONAL DE HISTÓRIA. Anais Anpuh Disponível em: $<$ http://anpuh.org/anais/index.php?s=iconografia + pict\%C3\%B3rica\&submit. $x=1$ 9\&submit. $y=19 \&$ submit=Buscar $>$. Acesso em: 15 maio 2014. 
ANPUH - ASSOCIAÇÃO NACIONAL DE HISTÓRIA. Revista Brasileira de História. Disponível em: <http://www.anpuh.org/revistabrasileira/public/8> Acesso em: 2 ago. 2014.

ARÓSTEGUI, Júlio. A pesquisa histórica: teoria e método. Bauru, SP: EDUSC, 2006.

ASHBY, Rosalyn. Desenvolvendo um conceito de evidência histórica: as idéias dos estudantes sobre testar afirmações factuais singulares. Educar em Revista, Curitiba, n. esp., p. 151-170, ago. 2006.

BURKE, Peter. Testemunha ocular: história e imagem. Bauru, São Paulo: EDUSC, 2004.

CAPES. Disponível em: <www.capes.gov.br> Acesso em: 14 maio 2014.

CECATTO, Adriano. O ensino da utilização de imagens pelos professores de história da Universidade Federal do Ceará (UFC). In: SIMPÓSIO NACIONAL DE HISTÓRIA, 27., 2013, Natal. Anais... Natal, 2013. Disponível em:

<http://www.snh2013.anpuh.org/resources/anais/27/1364339529_ARQUIVO_A_ utilizacao_de_imagens_pelos_professores_de_Historia02.pdf>. Acesso em: 23 jul. 2014.

COOPER, Hilary. O ensino de história na educação infantil e anos iniciais: um guia para professores. Curitiba: Base Editorial, 2012.

ENCONTRO NACIONAL PERSPECTIVAS DO ENSINO DE HISTÓRIA, 9.; ENCONTRO INTERNACIONAL DO ENSINO DE HISTÓRIA, 4., 2015, Belo Horizonte. Disponível em: <http://www.fae.ufmg.br/perspectivas2015/> Acesso em: 15 jun. 2015.

FORQUIN, Jean-Claude. Escola e cultura: as bases sociais e epistemológicas do conhecimento escolar. Porto Alegre: Artes Médicas,1993.

FRASCINA, Francis et al. Modernidade e modernismo: a pintura francesa no século XIX. São Paulo: Cosaic \& Naif, 1998.

PANOFSKY, Erwin. Iconografia e iconologia: uma introdução ao estudo da arte na renascença. In: - Significado nas artes visuais. Tradução de Maria Clara F. Kneesse e Jacó Guinsburg. 3. ed. São Paulo: Perspectiva, 1991. p. 45-65

PEREIRA, Walter L. C. de M. Imagem, nação e consciência nacional: os rituais da pintura histórica no século XIX. Cultura Visual, Salvador n. 17, p. 93-105, maio 2012.

PINTURA HISTÓRICA. In: ENCICLÓPEIDA ITÁU CULTURAL. Disponível em: $<$ http://enciclopedia.itaucultural.org.br/termo327/pintura-historica>. Acesso em 17 jul. 2015a.

PINTURA HISTÓRICA. In: WIKIPÉDIA: Enciclopédia Livre. Disponível em: <https://pt.wikipedia.org/wiki/Pintura_hist\%C3\%B3rica> Acesso em: 17 jul. 2017b. 
RÜSEN, Jörn. ¿Qué es la cultura histórica? reflexiones sobre una nueva manera de abordar la historia. Traducción de F. Sánchez Costa e lb Schumacher. Keulen, Weimar and Wenen: Böhlau, 2009a. p. 3-26. Disponível em:

<http://www.culturahistorica.es/ruesen/cultura_historica.pdf>. Acesso em: 28 maio 2015.

RÜSEN, Jörn. Aprendizagem histórica fundamentos e paradigmas. Curitiba: W. A. Editores, 2012.

RÜSEN, Jörn. Como dar sentido ao passado: questões relevantes de meta história. História da Historiografia, Rio de Janeiro, n. 2, mar. 2009b.

RÜSEN, Jörn. Razão histórica: teoria da história, os fundamentos da ciência histórica. Brasília: UNB, 2010.

SCHMIDT, Maria Auxiliadora; BARCA, Isabel. Aprender história: perspectivas da educação histórica. Ijuí: Unijuí, 2009.

SCHMIDT, Maria Auxiliadora; CAINELLI, Marlene. Ensinar história: pensamento e ação na sala de aula. São Paulo: Scipione, 2010.

VIEIRA, Jucilmara Luiza Loos. Cultura histórica e cultura escolar: diálogos entre a iconografia pictórica histórica e o ensino de história. 2015. Dissertação (Mestrado em Educação) - Universidade Federal do Paraná, Curitiba, 2015. 